\title{
La planificación estratégica participativa. Conceptos e instrumentos para nuevos modelos de gestión pública
}

Participative strategic planning: Concepts and tools for new schemes of public management

\section{Isidoro Felcman}

Doctor en Ciencias Económicas.

Director del Centro de Investigaciones en Administración Pública de la

Facultad de Ciencias Económicas de la Universidad de Buenos Aires.

Profesor consulto de la UBA.

ifelcman@gmail.com

\section{Gustavo Blutman}

Doctor en Ciencias Económicas. Secretario Académico del Centro de Investigaciones en Administración Pública de la Facultad de Ciencias Económicas de la Universidad de Buenos Aires.

Profesor titular de Administración Pública. blutman@gmail.com

Fecha de recepción:

29.9.17

Fecha de aceptación:

17.12.17

\section{Resumen}

Hay una idea relativamente generalizada en teoría y práctica de la planificación: pensarla como desarrollo de una lógica estratégica elaborada por expertos en el aislamiento controlado que proporcionan gabinetes y escritorios. Este artículo pretende destacar la existencia de una segunda lógica, la participativa, que no tiene la misma difusión que está teniendo la planificación estratégica en su sentido tradicional. Ambos elementos, estrategia y participación, se vinculan sinérgicamente en un ámbito específico: el sector público. Desde esta mirada nos proponemos sistematizar la información acumulada en una síntesis que pueda resultar comprensiva y práctica para su utilización en la gestión pública e impulsar acciones de Planificación Estratégica Participativa en la Administración Pública. La idea es poner énfasis en esa planificación que, desde el Estado, pretende promover a través de un rol activo una visión compartida de todos los actores sociales y de mercado, para obtener como producto final un proyecto colectivo de futuro. Este enfoque sostiene la centralidad que desempeña el Estado en la vida social como garante del bien público, siguiendo la idea de generar una visión compartida y la elaboración de un proyecto colectivo. La metodología de la planificación estratégica participativa pretende 
que el producto final de la misma pertenezca al conjunto de la sociedad y no sólo a un gobierno que circunstancialmente impulsa el proceso.

Palabras clave: planificación - estrategia - participación - Estado - administración pública

\begin{abstract}
There is a relatively widespread idea in theory and practice of planning: thinking about it in terms of a logical sequence of steps developed by experts in the isolation of desks and cabinets. This article aims to highlight the existence of a second logic, the participatory; this perspective does not usually have the same diffusion that is taking the strategic planning in the traditional sense. Both elements, strategy and participation, are synergistically linked in a specific area: the public sector. From this point of view, we intend to present a synthesis that can be comprehensive and practical for use in public management.
\end{abstract}

Our purpose is to emphasize the central role the state displays in planning, since it aims to promote a shared vision of all stakeholders, in order to obtain a collective future project as a final product. This approach maintains the centrality of the State in social life as a guarantor of the public wellbeing, according to the idea that, in the end, strategic plans belong to the whole society and not only to the government which gave only the primary impulse to the process.

Key-words: planning - strategic planning - participation - state - public administration

\title{
1. Acercándonos a la planificación estratégica participativa: algunas ideas centrales
}

Existen conceptos que vienen repitiendo diferentes autores y organizaciones en el sector público y privado: pensar la planificación como desarrollo de una lógica estratégica. Este artículo pretende destacar la existencia de una segunda lógica, la participativa; 
este valor agregado no tiene la difusión que está teniendo la planificación estratégica en su sentido tradicional. Ambos elementos, estrategia y participación, se conjugan en un ámbito específico, el que seleccionamos: el sector público. Desde esta mirada nos proponemos sistematizar la información acumulada en una síntesis que pueda resultar comprensiva y práctica para su utilización en la gestión pública.

A inicios de 2009 escribimos una serie de artículos sobre un fenómeno socio-económico y político que nos golpeó con fuerza como sociedad y como individuos, pero más especialmente a quienes nos dedicamos al estudio y la praxis de transformar la realidad desde las organizaciones públicas. Hacemos referencia a la implosión financiera mundial de 2008 (Felcman y Blutman, 2011). En aquel momento denominamos a los cambios en la manera de pensar lo público como "el big bang paradigmático", por las implicancias que, aunque en principio fueron solo eventos puntuales, tuvieron luego a nivel de las ideas y fundamentos sobre la economía, la política, la sociedad y también la gestión de lo público. Se estaba gestando allí un cambio de paradigmas, una nueva forma de ver el mundo.

Varios pensadores anticiparon la crisis: los premios Nobel Paul Krugman y Joseph Stiglitz, cuando criticaron con fuerza el fundamentalismo del mercado subyacente al Thatcherismo, la Reaganomía y el Consenso de Washington;Amartya Sen, otro premio Nobel, cuando habla de la economía con rostro humano; Bernardo Kliksberg, al defender y anticipar una nueva época donde se habrán de instalar definitivamente una economía al servicio de la humanidad, la ética en el mundo de los negocios, la responsabilidad social empresaria y un nuevo Estado inteligente capaz de impulsar procesos de crecimiento económico y desarrollo con inclusión social, promoviendo el bienestar general de la sociedad por encima de los intereses particulares (Sen y Kliksberg 2007).

En concreto, lo que era aceptado algunos años atrás como paradigma predominante hoy se pone en duda. El paradigma neoliberal individualista, hasta hace pocos años vigente, instrumentado mediante tecnologías de gestión pública denominadas del New Public Management (NPM), parece haber estallado y, adoptando la metáfora del big bang, sus diferentes fragmentos giran en un "espacio interparadigmático" (Felcman, 2017).

Ahora bien, este cambio paradigmático, ideológico y conceptual requiere de modelos y tecnologías de gestión apropiadas cuando es necesario pasar a la acción. Si pensamos en un Estado burocrático-weberiano tradicional, las tecnologías de gestión deberán garantizar la estandarización de procesos y la impersonalidad decisoria. El Estado neoliberal tuvo su expresión tecnológica apropiada en la desregulación y las privatizaciones. Si, en cambio, pensamos en ese nuevo modelo de Estado inteligente y participativo, las tecnologías de gestión congruentes con dicho modelo deberán diseñarse para horizontalizar los vínculos, promover la participación de actores clave en la formulación de políticas y, finalmente por esa vía, lograr involucramiento y compromiso del mercado y la sociedad 
con un proyecto colectivo. Nadie se compromete sin haber sido previamente involucrado, y nadie se involucra sin haber sido convocado a expresar ideas, formular propuestas, aportar a la generación de una visión compartida de futuro.

El abordaje que proponemos cobra importancia si pensamos que, en la actualidad, el fortalecimiento de las democracias no depende únicamente de arreglos institucionales que promuevan reglas o procedimientos formales, sino que además, se trata de generar capacidades que permitan la gestión de redes de actores, definidos por los procesos de interacción que se establecen entre ellos.

Adicionalmente, también debe señalarse que la planificación estratégica participativa es la tecnología de gestión más apropiada a esa concepción ideológica de lo público, porque está basada en la participación de todos los actores de un sector u organización. Estos, bajo la articulación del Estado, elaboran el análisis sistemático e identificación de la brecha existente entre una situación requerida a futuro (visión, misión, valores, fines estratégicos y objetivos) y una situación actual (fortalezas y debilidades), teniendo en cuenta escenarios futuros más probables (oportunidades y amenazas) y promoviendo participativamente la elaboración de políticas, planes y acciones destinados a transformar lo que se tiene en lo que se quiere (metas). Todo ello se elabora colectivamente generando como producto final una visión compartida de futuro.

A lo largo de varias décadas el planeamiento normativo fue el método más utilizado y el que está más instalado en los registros históricos. Pero el análisis de experiencias de este tipo de planificación ha revelado las dificultades que presenta el enfoque en un mundo en constante cambio. Así, la planificación estratégica se ha desarrollado contemporáneamente siguiendo otros enfoques y dando origen a otras metodologías.

La idea es poner énfasis en la planificación estratégica participativa que, desde el Estado, pretende promover a través de un rol activo una visión compartida de todos los actores sociales y de mercado, para obtener como producto final un proyecto colectivo de futuro. Este enfoque sostiene la centralidad estatal en la vida social como garante del bien público, siguiendo siempre la idea de generar una visión compartida y la elaboración de un proyecto colectivo.

Como puede verse, existen fuertes vinculaciones entre paradigma, ideología, modelo de gestión y tecnología. Si queremos instalar efectivamente un Estado inteligente y participativo, la tecnología de gestión a utilizar debe ser pertinente a dicho fin. El planeamiento normativo y el estratégico participativo son la expresión tecnológica de dos paradigmas, ideologías y modelos de gestión distintos.

Nuestra experiencia en el Plan Nacional del Seguro (PlaNeS), en el Plan Estratégico Agroalimentario y Agroindustrial (PEA) y en el Programa de Modernización de la 
Cámara de Diputados de la Nación (HCDN), permitió generar un proceso sistemático que, siguiendo un método ordenado de sucesivos pasos, tuvo la virtud de poner en juego no sólo la capacidad de los actores sociales para interaccionar colectivamente en ámbitos que generaron confianza y visión compartida de futuro, sino también la voluntad manifiesta del Estado de dialogar activamente con todos los actores sociales y del mercado, articulando intereses sectoriales para alcanzar una visión colectiva de futuro construida participativamente. Este este proceso fue plasmado en una metodología de Planificación Estratégica Participativa (PEP) (Felcman, Blutman et al. 2017)

Finalmente, desde la conducción del Estado debieron aparecer los que habitualmente se denominan líderes contraculturales, aquellos que son capaces de desafiar lo establecido y aventurarse en territorios inhóspitos, inexplorados, llenos de dificultades a sortear. Son los líderes pioneros, aquellos que se enfrentan a la cultura existente y generan una nueva forma de pensar y gestionar, afrontando con valentía la resistencia inicial, porque tienen fe en su proyecto y perseveran hasta verlo transformado en el proyecto del conjunto. El PlaNeS, el PEA y el Programa de Modernización de la HCDN pudieron llevarse adelante gracias a estos líderes contraculturales (Felcman, 2017).

En el presente trabajo nos proponemos responder preguntas básicas pero necesarias: ¿por qué y para qué planificar estratégicamente? ¿De qué hablamos cuando hablamos de planificar estratégicamente? ¿Cómo funciona la planificación estratégica participativa? ¿Qué métodos son factibles de utilizar? ¿Con qué herramientas podemos contar?

El gobierno como representante y conductor del Estado, el mercado como generador básico de riqueza y la sociedad como última beneficiaria de estos emprendimientos, pueden mostrar proyectos compartidos de futuro como fruto del rigor metodológico combinado con la inteligencia, la madurez y la voluntad de construir colectivamente un país mejor.

\section{Planificación estratégica participativa: marco conceptual y metodológico}

\subsection{Conceptos, metodología e instrumentos}

Mucho se ha escrito, pensado y repensado a la hora de formular propuestas vinculadas a la mejora de las capacidades del Estado, su rol y la vinculación que, como instancia de orientación estratégica y articulación social esencial en el ámbito de una sociedad organizada, debe desarrollar aquel con los actores del mercado y de la sociedad civil. Esta evolución en el pensamiento y la acción se dio con fuerza desde la misma instalación del paradigma jerárquico-weberiano y su modelo de gestión burocrático, pero se evidenció de manera más acelerada muy especialmente en estos últimos 30 años. Habiendo atravesado el Estado fuertes procesos de reformas estructurales, se pone hoy nuevamente de manifiesto la necesidad de una reconstrucción institucional sobre nuevas bases ideológico-conceptuales 
y nuevos modelos y tecnologías de gestión que permitan mejorar las capacidades estatales para la resolución de problemas (Kliksberg, 2011 en Felcman y Blutman, 2011).

La necesidad de mejorar los procesos de formulación y ejecución de políticas públicas implica disponer de tecnologías de gestión apropiadas para tener razonables probabilidades de éxito. Un recorrido histórico sobre la temática permite visualizar que a través del tiempo las organizaciones públicas y privadas han desarrollado diversas tecnologías de gestión orientadas a mejorar sus productos y procesos, en el marco de un mayor involucramiento de la sociedad civil en el accionar público (Felcman, 2015).

Una tecnología de gestión puede ser entendida como un conjunto de procesos más o menos estandarizados de planificación, organización, coordinación, dirección y control en el ámbito de las organizaciones; en definitiva, se trata de métodos, técnicas e instrumentos para la mejora de la eficacia y la eficiencia del funcionamiento organizacional (Suárez y Felcman, 1974). Asimismo, en un recorrido histórico puede observarse una evolución acelerada de dichas tecnologías desde fines del siglo XIX hasta nuestros días, con una tasa de innovación exponencialmente creciente, desde fines de los años 70s a la actualidad en el ámbito de las organizaciones públicas (Felcman, Blutman et al., 2013; Felcman, 2015; Pollit y Bouckaert, 2011; Osborne y Gaebler, 2002).

Es objetivo de esta publicación realizar aportes y precisiones sobre un marco conceptual, una metodología y una tecnología de gestión de planificación estratégica participativa que contribuya al desarrollo de las capacidades efectivas del Estado, a fin de responder con mayores niveles de especialización a las demandas que presenta el entorno generalmente atravesado por circunstancias cambiantes.

La planificación estratégica participativa es una herramienta que permite la toma de decisiones sobre la base de dos lógicas centrales: la metodológica y la participativa. La primera, destinada a identificar y luego cerrar la brecha entre una situación deseada y la situación existente a través de la formulación de políticas públicas; la segunda, a generar el involucramiento y compromiso de los actores sociales a través de la generación de visiones compartidas de futuro en la creencia que, sin la participación de dichos actores, todo plan estratégico tiene como destino final los anaqueles de las bibliotecas universitarias (Felcman et al., 2013).

El enfoque mencionado sitúa a esta tecnología de gestión en un lugar diferencial en relación a otras, dada su capacidad para interactuar en una complejidad horizontal, consultiva y de poder difuso, combinando virtuosamente la estructura jerárquico-burocrática característica del ámbito estatal y la consideración simultanea de actores relevantes del contexto, en concordancia con la exigencia de nuevos modelos organizacionales postburocráticos (Felcman, 2015). 


\subsection{Fundamentos teóricos}

La planificación puede considerarse bajo dos perspectivas de diferente escala: la institucional y la sectorial. La primera, enfocada al proceso intraorganizacional, y la segunda referida a un sector específico (de la economía, de lo social, de lo político, etc.).

Es importante señalar que si bien ambos son funcionales al mejoramiento del diseño e implementación de políticas, este trabajo se enmarca dentro de la segunda de las corrientes; aunque, sin duda, el planeamiento estratégico de carácter institucional se convierte en una condición necesaria para tener mayores posibilidades de éxito en la implementación de la herramienta.

Un plan estratégico participativo busca señalar un rumbo en el marco de escenarios futuros probables que involucre a actores, los comprometa y proporcione de esta manera a la gestión pública de un modelo y un conjunto de metodologías y técnicas, diseñadas para lograr consistencia y coherencia entre los objetivos estratégicos de determinado sector, con los objetivos de las organizaciones públicas y de los actores del mercado y la sociedad civil que en él operan.

La etimología de estrategia indica que deriva de los conceptos griegos "strategike episteme" (la visión general) y "strategonsophia” (la sabiduría general). Este concepto es usado en el lenguaje cotidiano para referirse a la definición de un camino a seguir para lograr uno o más objetivos, en un determinado plazo y a través del uso de medios específicos para alcanzarlos. Al igual que planificación, estrategia es un concepto vinculado con el ámbito militar asociado al desarrollo de la guerra, a partir del cual se piensan pasos necesarios para obtener mayores probabilidades de éxito y con ello, el logro de una victoria. Asimismo, Sun Tzu (2009) enfatizaba el carácter prescriptivo del concepto al señalar que los que son expertos en el arte de la guerra someten al enemigo sin combate, toman las ciudades sin efectuar el asalto y derrocan a un Estado sin operaciones prolongadas.

En América Latina la discusión sobre planificación se inicia a finales de 1960, adquiere popularidad a mediados de 1980, y tiene su auge a principios del 2000 como un componente fundamental en los procesos de reforma del sector público (Pichardo Muñiz, 2013).

El concepto de planificación adquiere relevancia al tener en cuenta que desde la década de 1980 la noción de incertidumbre ha evolucionado, pasando a ser considerada como una desviación ocasional y temporal de una predicción razonable, en lugar de una característica estructural, básica e inevitable del entorno (Shoemaker, 1995). La crisis de esta concepción mecanicista del mundo, donde las explicaciones causales permiten creer en un futuro controlable y predecible y donde las acciones se reducen a comportamientos medibles y regulares, ha generado la necesidad de combinar planificación 
estratégica con pensamiento estratégico para desarrollar políticas que contemplen la complejidad que involucran los procesos sociales (Felcman y Blutman, 2011).

De forma general, el pensamiento estratégico puede entenderse como la capacidad para resolver con éxito los problemas en forma individual y colectiva; vale decir, para asumir una tarea de alto nivel de complejidad, tomar decisiones estratégicas con autonomía (sin una guía o supervisión externa muy cercana) y responsabilizarse por sus resultados en el futuro (Mant, 1996). De esta manera, se entiende que un plan es un instrumento metódicamente organizado que aspira a obtener ciertos objetivos en el futuro.

Por su parte, el PNUD define planificación como "el proceso de establecer objetivos, desarrollar estrategias, trazar los planes de implementación y asignar recursos para alcanzar esos objetivos" (PNUD, 2009, p. 7). Tomando como punto de referencia algunas de las prácticas preponderantes en la región en materia de planificación, sobresale el caso del trabajo realizado por CEPAL a través del Instituto Latinoamericano y del Caribe de Planificación Económica y Social (ILPES) de la Comisión Económica para América Latina, cuyas investigaciones desplegadas en el área de planificación para el desarrollo se orientan al fortalecimiento de capacidades estatales en temáticas relacionadas con prospectiva, gestión estratégica y desarrollo territorial para la región.

Hace ya algunos años, la planificación orientada a resultados se ha consolidado gradualmente como un pilar fundamental de la gestión. Esto se produjo en el contexto de los nuevos enfoques que resaltan la importancia de las instituciones y su legitimación, en función de su capacidad de conducir y resolver los principales problemas vinculados a la problemática pública y de propender al mayor bienestar de cada uno de los miembros de la sociedad. Al respecto, uno de los principales roles del Estado es orientarse hacia las necesidades del ciudadano a fin de proporcionarle los resultados que éste demanda. Desde esta perspectiva, se promueven varias líneas de acción en la modernización del sector público: 1) la descentralización; 2) la provisión de más servicios y de mejor calidad; 3) la mayor transparencia y el control social; y 4) la responsabilidad conjunta del sector público y el privado en diversas áreas (Indes-BID, 2011).

Según señala Sandoval Escudero (2014), el concepto de planificación incluye entender la complejidad y su estudio multidisciplinario, la realización de diagnósticos y definición de objetivos. Se incluye la idea de la política y de un proyecto político. Es un proceso de gestión continuo asociado a la dirección de quien conduce y es el nodo para la construcción de grandes visiones colectivas de desarrollo.

El concepto de planificación estratégica ha evolucionado como una forma de abordaje renovado para la planificación, caracterizándose por el reconocimiento de una multiplicidad de actores y eventos frente a los cuales se define la actuación planificada, la consideración del 
mediano y largo plazo, así como horizontes temporales y la importancia del entorno en que se planifica (Pichardo Muñiz, 2013). La planificación estratégica permite pasar del plano de las ideas y la construcción de una visión a la transformación de la realidad. Efectivamente, eso es una tecnología de gestión, un conocimiento utilizable o utilizado para transformar una realidad (de gestión organizacional) en un sentido deseado (Suárez y Felcman, 1974).

\subsection{Planeamiento normativo, planeamiento situacional y planeamiento estrategico participativo}

En la búsqueda de antecedentes sobre la herramienta de la planificación participativa, se pueden identificar estas grandes dimensiones:

\subsubsection{Planeamiento normativo.}

Plantea la necesidad de definir objetivos explícitos, científicamente construidos, para las nuevas preocupaciones que surgen después de la conformación de los estados nacionales modernos. Su énfasis está en el ordenamiento en el tiempo del desarrollo de proyectos, programas y medidas políticas conducentes a lograr los objetivos globales de la estrategia de desarrollo (Sandoval Escudero, 2014).

La planificación normativa es la forma convencional de planeamiento mediante el cual un equipo técnico presenta un esquema de objetivos y metas que expresan lo deseable para ese conjunto de expertos. El producto más destacado de este tipo de planeamiento es el denominado Plan Libro, documento creado bajo una racionalidad técnica que establece una única y mejor manera de realizar las cosas. El rol de estos expertos es fundamental en su elaboración y es el centro de su diseño. El actor que planifica y gobierna el proceso es uno solo, se asume con un poder absoluto y con una visión única y hegemónica, en tanto el resto de los actores son simples ejecutores de una voluntad superior. El supuesto básico es que el actor planifica por encima de la realidad planificada y no coexiste en esa realidad con otros actores que también planifican (Matus, 1987).

En base a esto, un plan se elabora de acuerdo al diagnóstico de sujetos planificadores y en el marco de un escenario social supuestamente predecible y certero. Desde este enfoque, los objetivos, metas, programas y acciones son entendidos como normas a cumplir independientes del contexto y de sus posibilidades de realización, ignorando la incertidumbre propia de los comportamientos de los actores, sus dificultades, contradicciones y oposiciones en los procesos sociales; sin requerir ningún intercambio social, compromiso y participación de los otros.

Desde esta perspectiva, no resulta necesario considerar los intereses sectoriales de actores diversos, ni los obstáculos y limitaciones que habitualmente condicionan la factibili- 
dad de cualquier plan. En efecto, el planeamiento normativo supone un conocimiento de la realidad presente que se explica y evalúa en función de un único diagnóstico, una predicción del futuro (un deber ser) y una intervención sobre dicha realidad para lograr la situación deseada por parte de la visión de un equipo técnico experto en la materia pero ajeno a la situación a modificar (Felcman y Blutman, 2011).

\subsubsection{Planificación estratégica situacional.}

Dentro de los principales antecedentes teóricos que se diferencian de las posturas normativas, se encuentran los desarrollos de Carlos Matus (1993) en relación a lo que denominó Planificación Estratégica Situacional (PES). Este enfoque sostiene que el Estado desempeña un rol central en la vida social como garante público, siguiendo siempre la idea de generar una visión compartida de futuro y la elaboración colectiva de un proyecto. En definitiva, la planificación estratégica situacional permite transformar un conjunto de intereses sectoriales en el interés colectivo y alcanzar el bienestar general de un sector.

En palabras de Matus (1993), la planificación estratégica situacional es un cuerpo teóricometodológico-práctico muy sólido, sistemático y riguroso que toma en consideración a varios actores (partidos políticos, gobernantes o dirigentes de organizaciones públicas, representantes de la sociedad civil, empresariales y sindicales) en un juego de conflicto y cooperación, su tema son los problemas públicos y es también aplicable a cualquier organismo cuyo centro de juego no es exclusivamente el mercado, sino el juego político, económico y social, y es por este motivo que se convierte en un aporte fundamental.

En este marco se sitúa la Planificación Estratégica Participativa: una metodología destinada a promover el diálogo, la visión del otro y la generación de una visión compartida de futuro, factible de ser puesta en marcha en contextos de incertidumbre e intereses heterogéneos.

\subsubsection{Planificación estratégica participativa.}

Es una tecnología de gestión basada en el análisis sistemático y la identificación de la brecha existente entre una situación requerida a futuro y una situación actual, teniendo en cuenta escenarios futuros más probables y elaborando políticas, planes y acciones destinados a reducirla (Felcman y Blutman, 2011).

El objetivo es integrar a los actores involucrados en el desarrollo en el proceso de planificación. La participación, en este sentido, se considera una condición transversal de los procesos de planificación, que se ha integrado en cierta medida a las diferentes escuelas metodológicas (Sandoval Escudero, 2014). 
Desde el enfoque participativo se pretende privilegiar la dimensión de los actores sociales, en procura de potenciar la generación de visiones compartidas de futuro que garanticen involucramiento y compromiso para la implementación de planes estratégicos.

Esta modalidad de planificación es una herramienta que estimula la percepción de las múltiples y complejas dimensiones y dinamismos sociales con vistas a incrementar la riqueza y eficacia del pensamiento y de la acción en la elaboración y ejecución de políticas públicas, dado que para encarar un verdadero proceso transformador de la gestión resulta imprescindible construir un saber técnico especializado que esté al servicio de objetivos políticos claros, e identificar a partir de él lo mejor y posible en cada momento y sector según las metas planteadas (Felcman, Blutman et al, 2012).

En ese sentido, la participación tiene como propósito facilitar la adhesión consciente de la ciudadanía a los objetivos que plantea la transformación que se impulsa, constituyendo un escenario en el que se invita a apropiarse de los desafios en dicha transformación. Lejos de constituir una invitación a legitimar lo que otros deciden, la participación es entendida como una oportunidad de protagonizar la mejora del sector de modo personal, sectorial o institucional y desde las propias capacidades. Ello implica poner en juego no sólo la capacidad de los actores sociales para interaccionar colectivamente en el marco de procesos y ámbitos que reconstruyan la confianza, sino también la capacidad del Estado para articular intereses sectoriales en pos de una visión colectiva de futuro construida participativamente. Reconstruir la confianza entre los actores y la capacidad del Estado para articular intereses sectoriales son desafios centrales en el marco de la transformación del Estado (Felcman y Blutman, 2011).

El planeamiento estratégico participativo es una herramienta para pensar y transformar la realidad con visión de futuro, y se desarrolla mediante un proceso que actúa como mediador entre el conocimiento de la realidad y la acción que se ha de emprender, entre el presente que se pretende cambiar y el futuro que se desea alcanzar colectivamente. La planificación estratégica participativa es una metodología destinada a promover el diálogo, la visión del otro y la generación de visión compartida, mediante un proceso que favorece el involucramiento y el compromiso con un futuro colectivo.

Para ello, se requiere de un tipo particular de conocimiento para la acción intencional y reflexiva, que necesita instalarse mediante la generación de un espacio donde se promueve el diálogo, destinado a que los actores puedan aportar al proceso de construcción colectiva del futuro. Los mecanismos que surgen son los de cooperación, cooptación, conflicto, persuasión, negociación, mediación, disuasión, los cuales se pondrán en juego en relación a un actor principal llamado Estado. 
En ese marco, la planificación estratégica participativa se sitúa como una herramienta privilegiada de transformación basada en el conocimiento teórico-práctico, capaz de promover el desarrollo de la sociedad a partir de la previsión del futuro y de un conocimiento preciso del tiempo presente, sobre un proceso consensuado de transformación de la realidad en el largo plazo. La planificación se convierte, además, en la herramienta de gestión participativa por excelencia, en perfecta concordancia con la exigencia de un nuevo modelo organizacional que busca el circuito virtuoso entre lo igualitario y lo participativo (Felcman y Blutman, 2011).

La clave del modelo de gestión participativa es involucrar a los actores del mercado y la sociedad en la formulación de políticas públicas y en la propia gestión. El Estado actúa liderando un proyecto colectivo y convoca a la participación activa, para luego generar involucramiento, elementos centrales de una visión compartida de modo de lograr efectividad en la implementación de políticas, programas y acciones. Su relevancia radica en las características específicas que posee la herramienta de la planificación estratégica participativa, para alcanzar un trabajo coordinado entre actores con identidades e intereses disímiles que conforman el territorio de la visión, pudiendo ello contribuir, como consecuencia del compromiso, hacia una visión compartida de futuro y a una mejora en la implementación de políticas públicas como producto de la elaboración de acuerdos, el alcance de consensos y la definición de líneas de acción cooperativas.

\subsection{Marco conceptual integrador}

Todo plan estratégico participativo requiere ser sustentado teóricamente por un marco conceptual integrador (MCI) con la idea de justificar y alinear todos los conceptos desarrollados, su importancia y los vínculos entre los conceptos. Asimismo, permite identificar la unidad de análisis y relacionar los conceptos que la caracterizan, lo que será de importancia al momento de fundamentar la lógica de trabajo.

El marco conceptual integrador (Gráfico 1) toma como unidad de análisis el sector a planificar, y un contexto con el cual interactúa. En cuanto a éste, se presentan dos dimensiones: el contexto de condicionamiento global y el de condicionamiento directo, ambos generadores de oportunidades y amenazas.

En el contexto de condicionamiento global se describen las tendencias que desde el punto de vista económico, social, político y demográfico condicionan al sector de referencia desde el mundo, la región y el país. El proceso de identificación se realiza habitualmente a través de la técnica de construcción de escenarios futuros más probables cuyas características principales se desarrollarán luego. 
En el contexto de condicionamiento directo se analizan e identifican los comportamientos de diferentes actores que interactúan e influyen sobre las diversas dimensiones del sector.

Fronteras adentro se deberán identificar una situación futura requerida/deseada y una situación actual/existente, la brecha entre ambas y un conjunto de políticas destinadas a reducirla. La situación actual, en función a la situación requerida, contribuye a visualizar fortalezas y debilidades, que combinadas con las oportunidades y amenazas, permiten construir la matriz F.O.D.A. a partir de la cual se elaboran estrategias para la definición de políticas públicas, y se construyen herramientas para su implementación, seguimiento y monitoreo.

Gráfico 1: Marco conceptual integrador

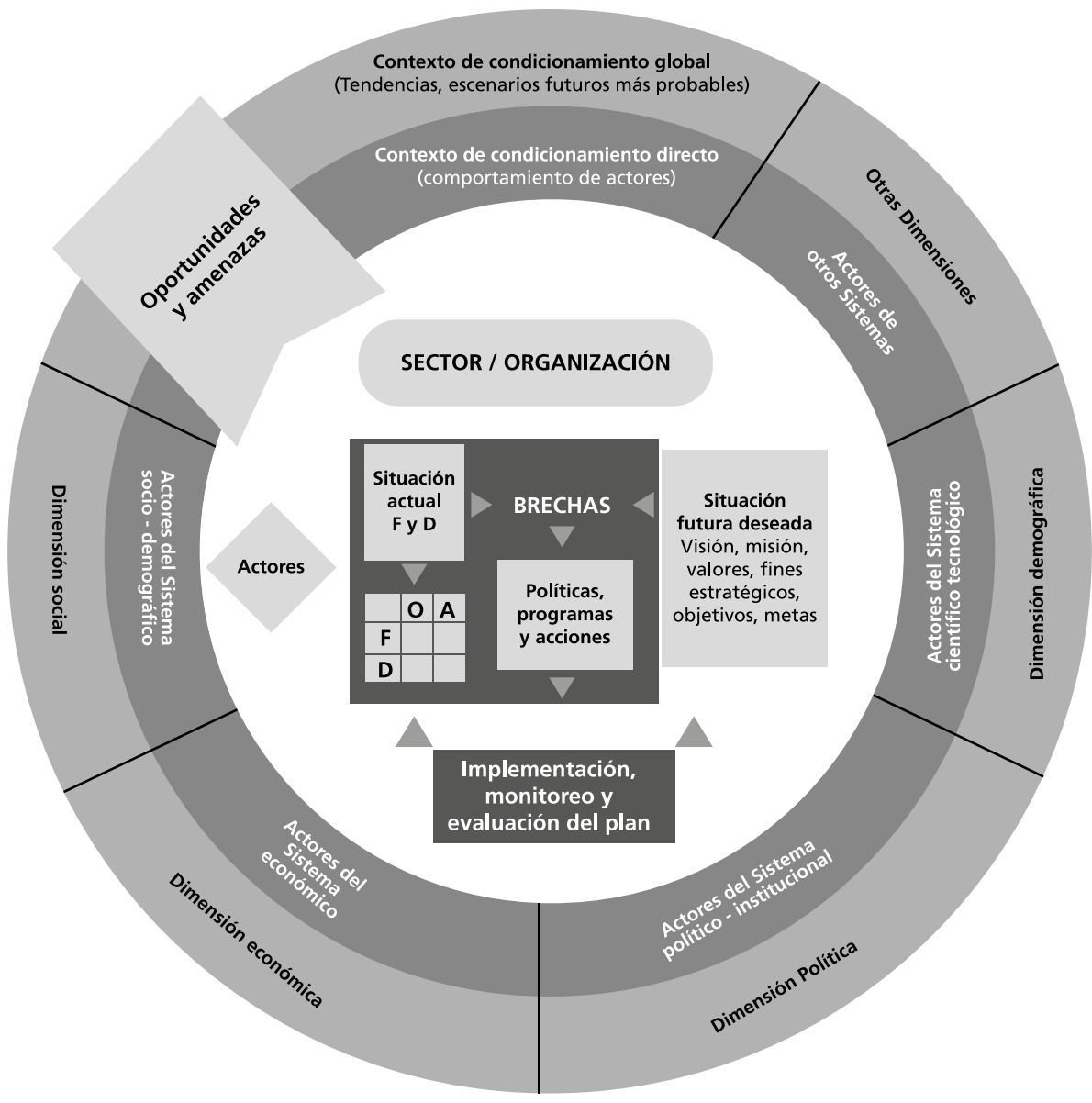

F: Fortalezas / D: Debilidades / O: Oportunidades / A: Amenazas 


\section{Construcción de la lógica metodológica: El método de los ocho pasos}

Desde el punto de vista metodológico, un plan estratégico se construye teniendo en cuenta dos dimensiones principales:

- Un proceso sistemático con secuencia de etapas, que se llamará lógica metodológica.

- Espacios, ámbitos y procesos especialmente diseñados para la elaboración colectiva del plan, que conformarán la denominada lógica participativa.

La lógica metodológica puede ser entendida como aquellos pasos sujetos a reglas lógicas y conceptuales necesarios para elaborar el Plan. Es un orden que se debe sostener en los diferentes procesos participativos para obtener una visión compartida y deseada de futuro colectivo. La idea central es clara: la participación sin método solo genera desorden y caos. Sin metodo no hay vision compartida de futuro.

La lógica que aquí se presenta se compone de ocho pasos que señalan el camino metodológico, que deberá ser empleado por todas las instancias de participación de los actores a lo largo del proceso en su conjunto.

Gráfico 2: El método de los ocho pasos

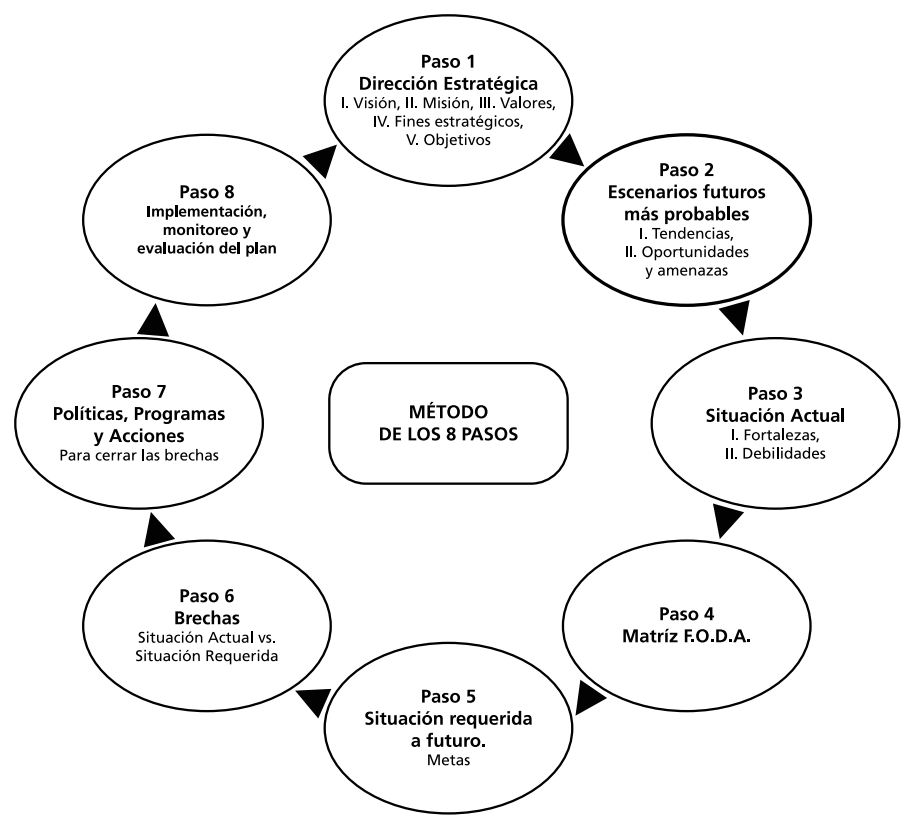




\section{Paso 1: Definición de la dirección estratégica}

La dirección estratégica está conformada por cinco componentes clave: la visión, la misión, los valores, los fines estratégicos y los objetivos. Ellos conducirán el accionar hacia las metas futuras deseadas, transformándose en nuestro horizonte.

La visión y misión se operacionalizan a través de una serie de fines estratégicos integrados por objetivos generales y específicos, que orientan luego políticas, programas y acciones y enlazan lo deseado con lo posible.

La dirección estratégica señala el horizonte al cual se pretende dirigir en un futuro predeterminado (Hax y Majluf, 1996). Se entiende, básicamente, como la adaptación de los recursos y habilidades disponibles a un escenario cambiante, aprovechando las oportunidades y evaluando los riesgos en función de objetivos y metas (Hermida, Serra y Kastika, 1992). En la planificación estratégica, la direccionalidad del proceso es fundamental (Ander Egg, 1995) ya que permite mantener el rumbo y la trayectoria para alcanzar determinadas metas y objetivos.

La estrategia, por su parte, es el procedimiento mediante el cual se procura encausar la dirección del proceso de desarrollo. Descansa en la previsión, es un estilo y un método de pensamiento acerca de la acción. Se encuentra sujeta a la percepción e interpretación dinámica del escenario en el cual se presentan intenciones, recursos y organización de los diferentes actores (Matus, 1987).

En definitiva, análisis y acción están integrados en la dirección estratégica, dado que se trata de un proceso continuo que orienta la toma de decisiones e intenta dar respuesta a las preguntas: qué hacer, cómo hacerlo, cuándo hacerlo y quién lo va a hacer.

La dirección estratégica, como se ha dicho, está conformada por los siguientes componentes: Territorio de la Visión, Visión, Misión, Valores, Fines y Objetivos Estratégicos.

\section{Definición del territorio de la Visión}

Alude al esquema conceptual y metodológico que sintetiza los múltiples aportes de los actores a medida que éstos participan y debaten acerca de la Dirección Estratégica. A partir de dichos aportes se construyen Territorios Comunes de Visión, Misión, Valores, Fines Estratégicos y Objetivos, los cuales permiten identificar grandes tensiones, que ponen a su vez de manifiesto los intereses particulares que cada actor expresa o defiende. Estos territorios definen entonces el espacio dentro del cual resulta posible la generación de consensos o visiones compartidas. 
En tal sentido, las principales tensiones, si bien involucran opiniones, aportes, ideas, intereses contrapuestos, no necesariamente deben ser vistas como divergentes. Muchas de ellas que, históricamente se consideraron opuestas, pueden ser consideradas como complementarias, contribuyendo a generar una visión compartida de futuro. Esto depende fuertemente de la habilidad de quienes conducen el proceso para identificar puntos intermedios en lugar de puntos extremos; en nuestras experiencias hemos podido generar las competencias para identificar dichos puntos intermedios.

\section{Definición de la Visión}

La Visión es un espacio referencial, una idea-fuerza que se ubica en un horizonte temporal lejano y describe una situación futura deseada vinculada a la identidad. Expresa la identidad futura que se desea alcanzar (Senge, 1990). Se construye laVisión respondiendo a la pregunta qué.

En el momento de hablar deVisión, se hace referencia a la identidad que se desea alcanzar en el futuro. Este ideario a alcanzar posibilitará la tarea de reflexión prospectiva. Un volver sobre el presente para estructurar la acción hacia el futuro deseado como paso previo a la definición de estrategias, políticas, cursos de acción y sus mecanismos instrumentales (programas, proyectos, presupuestos). La definición de la Visión acompaña al proceso de planificación estratégica desde los comienzos de su ejercicio.

La idea central de Visión Compartida es la posibilidad que tienen todos los actores de elaborar colectivamente una perspectiva de identidad futura. Esto no significa que existan solo posiciones similares. Una visión compartida también incluye miradas divergentes e ideas provenientes de variadas concepciones. Sin embargo, el marco conceptual y metodológico que guía el intercambio participativo permitirá la construcción balanceada de una visión compartida, donde las discrepancias puedan ponerse de manifiesto y, eventualmente, generar procesos de negociación destinados a lograr acuerdos.

\section{Definición de la Misión}

La Misión es el fundamento de prioridades, estrategias, planes y tareas. Es el punto de partida para el diseño del trabajo (David, 2003). Es aquello que señala el rumbo, orienta las actividades presentes y futuras proporcionando una dirección y guía en la toma de decisiones estratégicas. Enuncia los principales fines estratégicos o propósitos generales. Si la Visión dice el qué, la Misión define el para qué.

La Misión es, en este esquema, el punto de partida para el diseño de fines estratégicos y objetivos. Es la guía o marco de referencia para orientar las acciones y enlazar lo deseado con lo posible (Franklin, 2004). De aquí, la trascendencia que tiene la misión, ya que le da sentido a las distintas políticas, programas y acciones destinadas a transformar lo que "tenemos" en lo que "queremos". 
En conclusión, Visión y Misión constituyen elementos claves de la metodología de planeamiento estratégico. Mientras la Visión describe la identidad futura deseada, la Misión, compuesta por una serie de fines estratégicos que orientan las acciones y enlazan lo deseado con lo posible (desagregados cada uno de ellos en un conjunto de objetivos componentes), operacionaliza lo descripto por aquélla (Senge, 1990).

\section{Definición de los Valores}

En la construcción de laVisión adquieren un papel importante los valores que ponen en juego los integrantes de un determinado colectivo social, ya que ellos remiten a ideales que condicionan la acción y establecen un marco de referencia para la misma. Si la planificación estratégica busca darle un curso determinado a esa acción, los valores son los pilares sobre los cuales se asentará la dirección de la misma.

En el marco de la dirección estratégica, los valores permiten formar un núcleo alrededor del cual se estructuren los motivos, los esfuerzos y acciones de todos los actores del Sector y eso es lo que posibilitará viabilizar una Visión Compartida de futuro.

Si la Visión habla del qué y la Misión del para qué, los Valores se construyen respondiendo a la pregunta cómo: ¿cómo queremos lograr el qué y el para qué? (Senge, 1990).

\section{Definición de los Fines y Objetivos Estratégicos}

La planificación estratégica procura que las proposiciones generales (visión y misión) se desagreguen luego en objetivos. Los objetivos se definen como descripciones de los resultados que se desean alcanzar.

Se trata de estados futuros deseados para un periodo de tiempo específico. Como se señalaba en el punto anterior, un eje estratégico enlaza lo deseado con lo posible. Es el blanco de la acción que permite organizar los medios hacia un lugar futuro que ha sido seleccionado y que convoca los esfuerzos por lograrlo.

En tal sentido, los objetivos son considerados como operacionalizaciones de los fines estratégicos. Pueden ser vistos como alcanzables por el Sector a partir de los recursos que dispone.

Toda misión lleva asociados una serie de fines estratégicos, que se presentan como espacios propositivos mediante los cuales resulta posible, fijar objetivos. Cada uno de estos fines estratégicos, habrá de desplegarse luego en objetivos, que se organizan a través de una serie de fines estratégicos que orientan luego políticas, programas y acciones y enlazan lo deseado con lo posible, desagregados, cada uno de ellos, en un conjunto de objetivos componentes (Senge, 1990). 


\section{Paso 2: Definición de los Escenarios Futuros más Probables}

Los escenarios son formulaciones conjeturales de situaciones posibles donde se combinan elementos invariantes, variantes y opciones que se desarrollan en la trayectoria que va desde la situación actual hasta la situación objetivo (Lafuente, 1996). Consiste en imaginar modelos de situaciones futuras, su evolución en un horizonte de tiempo determinado y las respuestas posibles que pueden utilizarse para promover los cambios deseados. Así, el escenario es el conjunto de condiciones hipotéticas y supuestos futuros más probables donde se sitúa y opera el Plan, y desde el cual derivarán las oportunidades y las amenazas a las que enfrentar.

El método de análisis de escenarios se ha adaptado a numerosos sectores (industria, agricultura, demografia, empleo) y se ha aplicado a diferentes niveles geográficos (países, regiones, mundo). Incorporado al planeamiento estratégico tiene por finalidad establecer referencias de situaciones futuras posibles para programar iniciativas y respuestas del actor que planifica. La esencia del análisis de escenarios consiste en plantear el problema de que no es posible conocer el futuro sino sólo prever algunas de sus posibilidades. El concepto de escenario en el Plan Estratégico Situacional es una herramienta para lidiar contra la incertidumbre (Matus, 2007).

El diseño y elaboración de escenarios es un ejercicio de imaginación acerca de futuros posibles. Es la construcción de hipótesis (o modelos básicos del comportamiento futuro) de la estructura que tendrá el escenario en un horizonte de tiempo determinado. El escenario es una conjetura que representa a los fenómenos que pueden acontecer y de sus conexiones de causa y efecto (hipótesis descriptiva y explicativa).

El análisis de escenarios debe considerar simultáneamente dos aspectos: el análisis competitivo y el análisis de tendencias.

Como señaló Porter (1993) hace tiempo y con vigencia en la actualidad, en la economía actual, globalizada y cada vez más competitiva, los factores tradicionales de la riqueza: tierra, recursos naturales y el trabajo ya no pueden producir y explicar por sí mismos las razones de por qué ciertos países generan mayor riqueza que otros. La clave está en la competitividad y particularmente en la productividad de las naciones y de sus sectores económicos en particular, la que se expresa en la diversidad de las exportaciones a diferentes lugares del mundo y en una sólida inversión fuera de las propias fronteras.

Por otro lado, resulta necesario identificar tendencias consideradas en base a variables económicas, sociales, demográficas, políticas, culturales, legales, científico-tecnológicas, históricas, las cuales serán sistematizadas como oportunidades y amenazas que afectan o pudieran afectar el futuro del Sector. Dichas tendencias pueden ser de carácter nacional, regional o internacional, de acuerdo al nivel en el que se sitúe el análisis. 
El análisis de tendencias no debe basarse exclusivamente en proyectar lo sucedido en el pasado hacia el futuro. Se han visto a lo largo de la historia rupturas de tendencias anteriores que generaron quiebres fundamentales en fenómenos económicos, sociales, políticos, tecnológicos y medio ambientales, entre otros. El análisis de tendencias finaliza con la identificación de oportunidades y amenazas:

- Oportunidades: son los factores y/o procesos externos que de manera directa o indirecta contribuyen al logro de los resultados propuestos. Las oportunidades son entendidas como "situaciones que se encuentran en el entorno y que pueden ser aprovechadas para facilitar el logro de objetivos, la realización de la misión y el cumplimiento de la visión propuesta" (Aramayo, 2006, p. 59).

- Amenazas: son los factores, personas o situaciones que, de manera directa o indirecta, influyen negativamente causando el retroceso, el debilitamiento o la destrucción de los fines propuestos

(Barzán, 2004).

La prospectiva como metodología de construcción de escenarios, lejos de pretender conocer el futuro, parte de asumir y reconocer la imposibilidad de poder adivinar las consecuencias del futuro. La actitud prospectiva, efectúa un movimiento de creatividad para lograr despertar insatisfacción por lo existente y desarrollar inquietudes, expectativas y aspiraciones a lograr y busca luego desprenderse de las rutinas a las que se está habituado.

\section{Paso 3: Definición de la Situación Actual}

La descripción de la situación actual supone identificar las diversas realidades problemáticas que hay que enfrentar. El resultado de este proceso es un esquema de condiciones que señala las fortalezas y debilidades que hay que asumir para determinar la capacidad que se posee para lograr los objetivos deseados (Bendlin, 2005).

En el punto anterior se presentó la necesidad de elaborar los escenarios futuros más probables a partir de la definición de tendencias que permitirá detectar oportunidades y amenazas que el entorno ofrece al Sector. La planificación estratégica también requiere del análisis de la situación actual, que se realiza en pos de conocer las condiciones de un sector y las causas de los problemas que pueden obstaculizar el cumplimiento de objetivos, misión y visión. 
Aquí aparece la noción de problema, que puede entenderse como toda diferencia entre la realidad actual y la realidad futura que se desea alcanzar.

- Fortalezas: características actuales propias del sector que se presentan como factores claves para aprovechar oportunidades. Se las puede definir como elementos que hacen un ambiente propicio para el desarrollo y necesarias para garantizar su utilización adecuada y para transformarlas en el fundamento de las decisiones estratégicas.

- Debilidades: características propias del sector, pero que representan factores que dificultan el desarrollo hacia objetivos deseados. Estas condiciones generan un ambiente desfavorable para el desarrollo y es importante conocerlas para impulsar estrategias que tiendan a superarlas.

\section{Paso 4: Definición de la Matriz y análisis F.O.D.A.}

El análisis F.O.D.A. es una herramienta para determinar estrategias en la búsqueda de un futuro deseado. F.O.D.A. es la sigla de Fortalezas, Oportunidades, Debilidades y Amenazas, variables que se fusionan gráficamente en un cuadro de doble entrada donde éstas se cruzan para su posterior análisis. Constituye una herramienta útil para la toma de decisiones sirviendo de apoyo al planeamiento, en cuanto posibilita una síntesis del diagnóstico actual y orienta las decisiones sobre estrategias. El análisis F.O.D.A. está relacionado a cómo se enfrentarán posibles amenazas y oportunidades teniendo en cuenta los recursos disponibles, que generan fortalezas y debilidades para alcanzar los objetivos planteados.

\section{Paso 5: Definición conceptual de Metas}

Por definición, las metas se establecen como indicadores para gestionar el avance hacia el logro de los objetivos propuestos, fijando las prioridades. En otras palabras, las metas son la cuantificación de los objetivos, y al igual que éstos deben ser medibles, coherentes, razonables, estimulantes y claras. Deben informar sobre cantidad, costo, tiempo, ser verificables y formularse a través de indicadores que permiten su cuantificación y posterior medición.

En tal sentido son fundamentales para la ejecución de las estrategias formuladas dado que forman la base para la asignación de recursos. Las metas se pueden proyectar a diferentes plazos (corto, mediano y largo). 
Cabe mencionar que cuando se habla de cuantificación, se hace hincapié en la utilización de escalas ordinales, cardinales y nominales. Las metas no son necesariamente de tipo cuantitativo, pueden ser cualitativas. Por ejemplo, hay acciones no cuantificables como la regulación de mercados, la formulación de políticas, metas de tipo normativo, cuya finalidad es otorgar un marco ético- político a la acción de las instituciones.

Así, la fijación de metas futuras es una mezcla equilibrada de deseos, caminos a seguir y empleo posible de recursos disponibles.

\section{Paso 6: Definición de las Brechas (situación actual vs. situación requerida)}

Las brechas se presentan como síntoma de disconformidad, insuficiencia o carencia presente y como un espacio abierto para la reflexión y la acción destinada a producir el cambio situacional para el futuro por medio de modificaciones en todas o algunas de sus dimensiones/aspectos. Hacen referencia a la distancia existente entre la situación actual y la situación deseada.

A través de un estudio de diagnóstico se puede efectuar un análisis de brechas en el cual se comparen ambas situaciones (actual y futura deseada). Mediante dicho estudio es posible identificar las dificultades que frenan la consecución de las actividades pautadas. Desde allí surge la posibilidad de cerrar las mencionadas brechas a través de la puesta en marcha de políticas, programas y acciones que colaboren a tal fin. En caso contrario, se deberá resignar metas futuras y pensar en metas menos ambiciosas. La elaboración de un plan estratégico supone la conexión entre el establecimiento de metas, objetivos y fines estratégicos y la identificación de brechas.

\section{Paso 7: Definición de Políticas, programas y acciones para cerrar las brechas}

Las políticas se definen como los grandes cursos de acción que se despliegan en programas, actividades y tareas que permiten cerrar la brecha existente entre la situación actual y la requerida. Deberán orientarse a la obtención de un producto final que garantice el logro de los objetivos propuestos. Suponen un conjunto de actividades interrelacionadas y coordinadas con el fin de alcanzar objetivos específicos dentro de los límites de un presupuesto y un período de tiempo dados.

Las políticas públicas son el resultado de la negociación entre intereses de los distintos actores sociales. Estos actores dirimen sus diferencias, negocian e intercambian recursos valiosos para cada uno de ellos en el marco de lo que Lowi (1972) denomina "arena de poder", la cual permite designar la sede del juego político (arena parlamentaria, arena burocrática, arena intrapartidaria, etc.). Cada tipo de política genera una arena de poder específica con su estructura característica, sus élites, su proceso político y sus relaciones o su forma de mediación de intereses. 
Las políticas públicas se operacionalizan por medio de programas que logran traducir los deseos de la organización en tiempo y espacio, en recursos requeridos y formas de organización. Sistematizan cómo, cuánto y quiénes habrán de desarrollar las acciones. Al mismo tiempo, evalúan y ordenan los procesos, los recursos y establecen la sucesión temporal de los objetivos. Constituyen un modelo operacional por medio del cual los objetivos específicos o inmediatos del plan, desagregados, se convierten en los objetivos generales o de desarrollo de los programas.

A su vez, los objetivos inmediatos de los programas derivarán en los objetivos generales de los proyectos, que son las unidades menores de implementación. Los programas están constituidos por un conjunto de proyectos que persiguen sus objetivos inmediatos. Los proyectos constituyen el eslabón final del proceso de planificación, suponen un conjunto de actividades interrelacionadas y coordinadas con el fin de alcanzar objetivos específicos dentro de los límites de un presupuesto y un período de tiempo dados. Por su parte, las acciones son la secuencia de pasos concretos que se realizan para alcanzar el logro de los objetivos.

\section{Paso 8: Definición de conceptos relacionados con la implementación, el monitoreo y la evaluación del Plan Estratégico Participativo}

Una vez elaborado el plan estratégico, el siguiente paso es iniciar su implementación, lo que implica un proceso de permanente seguimiento y monitoreo de las acciones y logros, a fin de reducir la diferencia entre la planificación (realizada en los pasos anteriores), su ejecución y los resultados obtenidos.

El monitoreo de resultados y la evaluación de impacto tienen la ventaja de brindar elementos fundamentales a los decisores de políticas públicas para que puedan tomar decisiones sobre el curso de acción y profundizar, modificar o rediseñar una determinada iniciativa. La información provista permite un mejor y más eficiente uso de los recursos, mejorar la definición de metas y plazos y facilitar el diseño de iniciativas futuras.

Si bien se encuentran interrelacionados, el monitoreo y la evaluación son procesos diferenciados. El monitoreo es continuo y permanente durante la ejecución del proyecto. La evaluación, en cambio, se realiza en períodos previamente establecidos y de forma regular y espaciada.

La evaluación es una valoración y reflexión sistemática sobre el diseño, la ejecución, la eficiencia, la efectividad, los procesos, los resultados (o el impacto) de un proyecto en ejecución o completado (Ortegón, 2005). Se lleva a cabo de forma sistemática en todas las etapas del ciclo del plan (su preparación, ejecución y operación post proyecto), requiere recursos específicos para llevarla a cabo (humanos, temporales y presupuestarios) y el establecimiento de un momento en el tiempo para realizar la evaluación y comparar la situación con el pasado. 


\section{Construcción de la lógica participativa}

La participación ciudadana en los procesos de políticas públicas constituye un elemento fundamental dado que es la condición de posibilidad para la construcción de gobernanza democrática y, en este sentido, puede llegar a constituir un mecanismo para el empoderamiento social.

Prats (2006) señala que "para que la gobernanza sea democrática implica la inclusión simétrica no sólo de los sectores público y privado, sino también del sector cívico-social. Para ello, es necesario que los intereses sociales tengan la oportunidad efectiva para organizarse, informarse y participar en la interacción decisional"' (p. 28).

Sin embargo, el desarrollo de un proceso participativo requiere de institucionalización: los actores involucrados deberán apropiarse de los espacios participativos, ocuparlos y utilizar los instrumentos que faciliten la sistematización de sus aportes.

Desarrollar políticas públicas enfocadas a la participación, o bien plantear la participación ciudadana como eje transversal de una gestión, no es sólo un asunto de técnica y eficiencia administrativa, sino sobre todo una cuestión ligada a la posibilidad de construir una mirada común del sector a planificar.

En este sentido, y en lo referido a la lógica participativa o método de participación que se propone, existen tres elementos claves que la sustentan:

- El rol de quien conduce el proceso de planeamiento y de los actores sociales.

- La lógica metodológica que guía el proceso de participación.

- El propio proceso de participación que, siguiendo una secuencia ordenada de actividades desarrolladas en ámbitos participativos, genera involucramiento y compromiso en todos los actores intervinientes y promueve una visión compartida y un proyecto de futuro elaborado colectivamente.

En la lógica participativa se establecen mecanismos de involucramiento a partir de la conjunción de diferentes actores sociales que, siguiendo una metodología de trabajo (lógica metodológica), pueden expresar sus expectativas, necesidades e intereses y poner en juego estrategias de cooperación, captación y conflicto, así como ejercitar la negociación, mediación, persuasión y disuasión. La lógica participativa da cuenta de cómo los actores se van incorporando al proceso, de qué manera lo hacen, en qué espacios y cuándo, y especialmente tiende a asegurar la interacción, la representación y el involucramiento de los actores en la elaboración del plan. 
Las lógicas metodológica y participativa deben combinarse virtuosamente; no son dos lógicas que operan por separado sino que ambas deben estar interrelacionadas. Los actores que participan del juego social no lo hacen de manera anárquica, sino que se inscriben dentro de dicho juego siguiendo de manera sistemática la lógica metodológica y su secuencia ordenada de pasos, comenzando por la dirección estratégica, luego la construcción de escenarios, etc. tal como se ha podido ver más arriba.

Para la construcción de una visión compartida de futuro sobre el sector a planificar se propone el siguiente mapa de procesos:

Gráfico 3: Mapa de procesos para la construcción de una visión compartida de futuro

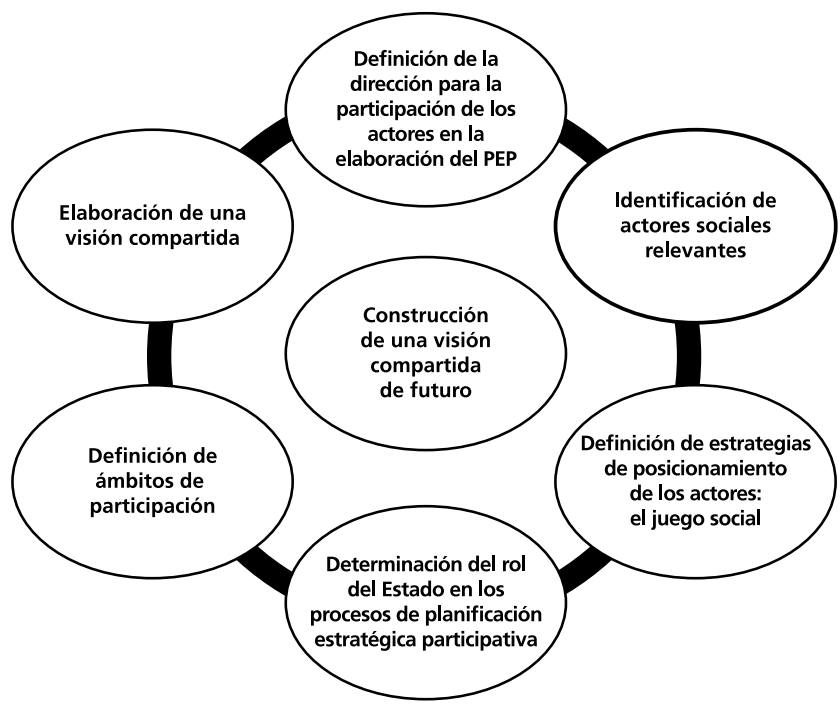

\section{Pasos para una metodología de Planeamiento Estratégico Participativo (PEP)}

\section{Paso 1: Definición de la dirección para la participación de los actores en la elaboración del PEP}

La construcción de visión compartida en el planeamiento estratégico implica tomar la decisión de hacia dónde ir y cómo hacerlo. Debe realizarse tomando en cuenta la opinión de los actores estratégicos, pues es la única manera de asegurar la apropiación y la credibilidad de un plan. 


\section{Paso2: Identificación de actores sociales relevantes}

No se pueden lograr resultados si la mayoría de los involucrados en la tarea no está explícitamente de acuerdo con el plan. Mientras mayor sea el grado de participación de los actores relevantes de la sociedad, mejores serán las posibilidades de que el plan se cumpla y de que sus logros sean sostenibles en el tiempo.

Siguiendo a Belmartino, se diría que son actores sociales "aquellos individuos o grupos que ocupan una posición estratégica en el sistema de decisiones y que responden, en el proceso de formación de políticas, por las funciones de articulación del campo cognitivo y del campo del poder" (1998, p. 2-3). Como participantes de la construcción de la realidad son quienes tienen intereses en los temas de debate y el marco en el cual se desarrollan las negociaciones, alianzas y conflictos que sustentan la toma de decisiones. Dado que estos actores poseen distinto grado de capacidad de daño e influencia, no pueden dejar de ser tenidos en cuenta a la hora de pensar un proceso de planificación.

Toda planificación supone la existencia de actores, admitidos como parte de la realidad que se intenta transformar. Los actores son dinámicos y operativos, se mueven e interaccionan en diferentes contextos y situaciones (Macchiarola de Sigal, 2006). Entenderlos como sujetos predecibles, sólo pasibles de movimientos mecánicos y reactivos, es reducir el análisis a una visión incauta que opaca la compleja realidad que se intenta abordar.

Los actores sociales son los principales agentes del cambio. Son los que toman posiciones y adoptan estrategias, como aliados u oponentes, expresando insatisfacciones o acuerdos, problematizando aquellas situaciones que les interesan o afectan de modo particular y desestimando otras.

No se trata de un juego donde los actores por acumulación toman una decisión colectiva y donde las individualidades pesan poco, sino más bien de un despliegue de pocos actores pero con un peso decisivo en la toma de decisiones, en representación de diversos tipos de organizaciones (jefaturas de partidos políticos, directivos de organizaciones gubernamentales, grupos de presión organizados, sindicatos, organizaciones religiosas, económicas y militares, entre otros). El análisis de la trayectoria de los actores permitirá construir un mapa de actores para tener una mejor aproximación y cierta previsibilidad respecto a las acciones o reacciones que puedan llegar a desarrollar.

\section{Paso 3: Definición de estrategias de posicionamiento de los actores: el juego social}

Los procesos políticos que se dan al interior de los subsistemas que conforman una sociedad no son únicamente aquellos en los que interviene el Estado; los mismos se 
encuentran a su vez atravesádos por relaciones establecidas entre actores que operan en el marco de relaciones de fuerza desiguales donde el Estado cumple un rol articulador.

Cada actor orienta su accionar motivado por intereses, dando lugar a lo que Matus (2000) denomina el juego de lo social, dando lugar a una diferenciación entre ellos. En palabras de Matus, “el juego de lo social exige diferencias. De otro modo no sería un juego de cooperación y conflicto en relación con los otros” (p. 166).

Por lo antedicho, el estudio de la participación de actores implica remitirse a analizar el entrecruzamiento de objetivos, intereses, valores y recursos que despliegan los actores estatales y sociales. El entendimiento de los posibles patrones de acción e interacción de los actores involucrados permitirá entender su rol en el proceso de políticas, permitiendo hablar de "juego social" (Oszlak, 2009).

Desde esta concepción el proceso de formulación de políticas debe entenderse como una red donde todos los actores participan y definen sus estrategias dependiendo de los recursos que se puedan movilizar, su conocimiento, sus percepciones y visiones estratégicas particulares.

Llevar adelante un proceso de planificación estratégica participativa implica gestionar la complejidad del juego social en términos de conocimiento, destreza y habilidades para la conducción de procesos en los cuales los actores generan y cambian recursos, procesos que se ven reflejados en las estrategias y juegos de los actores que la conforman.

\section{Paso 4: Determinación del rol del Estado en los procesos de planificación estratégica participativa}

Pensar en transformar las estructuras organizacionales e incorporar tecnologías de gestión apropiadas para dicha transformación requiere discutir acerca de qué papel se desea que cumplan el Estado y su aparato.

Tal como se ha señalado anteriormente, las reformas estatales han vuelto a poner en el centro de los debates el rol y la capacidad del Estado, así como la necesidad de una reconstrucción institucional sobre nuevas bases para formular e implementar políticas públicas de manera exitosa. Se puede mencionar una cantidad importante de países que a principios de la década de 1980, en el mundo desarrollado, han implementado algún tipo de reforma, sumándose en la década siguiente otras experiencias en algunos países emergentes (Argentina entre ellos), y una profundización de las líneas originales en el Reino Unido, Estados Unidos y Nueva Zelanda, entre otros (Blutman, 1998).

Se podría decir que si las décadas de 1980 y 1990 estuvieron caracterizadas por el diseño e instalación del Estado mínimo, a partir del 2003 se visualiza una ruptura paradigmática respecto 
del rol estatal; asistiendo a un proceso de reconstitución y reposicionamiento del Estado como un actor más activo en las distintas esferas sociales y económicas (Felcman y Blutman, 2011).

A partir de esta circunstancia, el objeto principal de debate en torno a la gestión pública se centra en la cuestión de los modelos organizacionales más apropiados para transformar las organizaciones públicas y hacerlas efectivas para la satisfacción de múltiples y complejas necesidades e intereses colectivo.

Felcman, Blutman y Méndez Parnes (2002) señalan:

Las capacidades efectivas para la formulación y ejecución de políticas públicas, en un marco de incremento de la calidad de las instituciones $y$ del involucramiento de la sociedad civil, se convierten en temas predominantes a tener en cuenta y con ello la calidad y relevancia del modelo y las tecnologías de gestión a utilizarse para tener razonables probabilidades de éxito (p. 87).

A partir de la elaboración colectiva del plan, se busca estimular la responsabilidad ciudadana y el involucramiento de los actores sociales, apuntalar un proceso de fortalecimiento institucional, construir un Estado fuerte, y finalmente vigorizar la relación entre el mercado, la sociedad y sus representantes políticos, lo cual implica poner en juego no sólo la capacidad de los actores sociales para interaccionar colectivamente, sino también la capacidad del Estado para alcanzar el crecimiento y desarrollo económico y social, a partir de una visión colectiva de futuro construida participativamente.

\section{Paso 5: Definición de ámbitos de participación}

La incorporación del componente participativo en el proceso de elaboración e implementación del PEP, se convierte en el elemento distintivo de esta tecnología ya que las políticas públicas no existen "naturalmente", sino que se trata de construcciones sociopolíticas. En este sentido, las políticas son consecuencia de la lucha entre diferentes actores con concepciones e intereses, visiones del mundo o paradigmas diversos.

En este marco, el proceso de diseño y formulación de políticas públicas requiere que el Estado opte por tener en cuenta sólo al gobierno como el líder de su formulación, o por permitir diferentes grados de participación de los actores involucrados a fin de alcanzar mayores niveles de consenso y aprobación de sus decisiones. Para ello, y dado que uno de los objetivos de la formulación del PEP consiste en generar confianza y visión compartida del sector a planificar, un requisito indispensable para el éxito de su implementación, es la institucionalización de los espacios que ordenen la participación. 


\section{Paso 6: Elaboración de una visión compartida}

Siguiendo a Senge (1990), en su análisis sobre la teoría de las organizaciones, una visión compartida es la respuesta a la pregunta: ¿qué deseamos ser?

Una visión es verdaderamente compartida cuando los involucrados construyen una imagen similar que crea una sensación de vínculo común que impregna la organización y brinda coherencia a actividades dispares. Cuando la gente comparte una visión está conectada por una aspiración común. Como afirma el autor:

Si una idea sobre el liderazgo ha inspirado a las organizaciones durante miles de años, es la capacidad para compartir una imagen del futuro que se procura crear. La práctica de la visión compartida supone aptitudes para configurar "visiones del futuro" compartidas que propicien un compromiso genuino antes que mero acatamiento. Al dominar esta disciplina, los líderes aprenden que es contraproducente tratar de imponer una visión, por sincera que sea.

(Senge, 1990, p.5).

¿Por qué importan las visiones compartidas? Porque despiertan el compromiso de muchas personas, ya que reflejan su visión personal. En una organización, una visión compartida modifica la relación de la gente con la organización. Es el primer paso para permitir que quienes se profesaban mutua desconfianza comiencen a trabajar en conjunto, construyan una identidad común, y encuentren coincidencias en su visión y valores.

Una visión compartida también brinda un timón para mantener el rumbo del proceso; con una visión compartida es más probable que los individuos expresen su modo de pensar, y acepten poner en un plano secundario perspectivas arraigadas y reconocer los defectos.

Si se adaptan estas reflexiones a la planificación de un sector específico, la construcción de una visión compartida de futuro implica identificar las tensiones que se generan producto de los diversos posicionamientos, y a partir de allí construir una mirada común basada en las coincidencias.

\section{Consideraciones finales}

En este trabajo hemos desarrollado la estructuración de los diversos componentes del Planeamiento Estratégico Participativo (PEP). Surge de nuestra exposición que no es el PEP una actividad simple: para llevarla a cabo se requiere tomar en cuenta una cantidad importante de actores, instancias, procesos, actividades, recursos y etapas. De esa exposición debería resultar claro también que para todo accionar es necesario un modelo conceptual y metodológico que contemple la propuesta de planificación. Si algo caracteriza al PEP es la 
flexibilidad para adaptarse a entornos cambiantes; diseñamos estrategias y documentos vivos que se van construyendo, reconstruyendo y deconstruyendo. Esto significa mejora continua.

Construimos prototipos evolutivos que permiten a los diseñadores e implementadores y a los actores en general, tener una comprensión cabal de todos los pasos de la planificación desde lo conceptual y lo metodológico a lo instrumental.

Finalmente, la idea principal a resaltar es que no existe posibilidad de pensar en el futuro sin un concepto y una metodología de planificación, pensada y luego ejecutada de manera estratégica y con el involucramiento y compromiso de los actores sociales a fin de alcanzar un producto final: la construcción de una visión compartida de futuro.

Siguiendo el pensamiento de Kierkegaard, podemos afirmar que "la vida puede comprenderse mirando hacia atrás, pero solo puede vivirse mirando hacia adelante". Sin mirada de futuro, el presente es solo consecuencia del pasado y, en cierta forma, solo un reflejo de lo que alguna vez sucedió. El planeamiento estratégico participativo nos ayuda a crear futuro, a tener proyecto y a poner en marcha recursos, esfuerzos y voluntades para alcanzar dicho futuro colectivamente. 


\section{Referencias bibliográficas}

Ander Egg, E. (1995). Introducción a la planificación. Buenos Aires, Argentina: Editorial Lumen.

Aramayo, O. (2006). Manual de planificación estratégica, Universidad de Chile, Instituto

Banco Interamericano de Desarrollo (2011). Curso de formulación de proyectos. Módulo 3: Herramientas para la gestión de proyectos. Recuperado en: http://courses.edx.org/ courses/course-v1:IDBx+IDB6x+2015_T2/pdfbook/0/.

Banco Interamericano de Desarrollo (2011). Curso de Gestión por resultados para el desarrollo en Gobiernos sub-nacionales. Módulo 2: La planificación orientada a resultados. Copyright INDES: Banco Interamericano de Desarrollo. Recuperado en: https://courses. edx.org/courses/course-v1:IDBx+IDB1x+2015_3T/pdfbook/0/.

Barzán, V. (2006). En Aramayo, O. Manual de Planificación Estratégica; Instituto de Comunicación e Imagen. Universidad de Chile.

Belmartino S., (1998). Nuevo rol del Estado y del mercado en la seguridad social argentina. Ponencia en el XXI Congreso Internacional de la Latin American Studies Association, Chicago.

Bendlin, C. (2005). Curso de Planificación Estratégica. Recuperado: http://www.cicoam.org. py/materiales/modulo2/Planificaci $\%$ F3n $\% 20 y \% 20$ Administraci $\%$ F3n\%20Financiera.ppt.

Bouckaert G. y C. Pollit, (2011). Public Managment Reform:A comparative Analysis - New Public Management, Governance and New Weberian State. Oxford: Oxford University Press.

CEPAL (2016) "Estado de la banda ancha en América Latina y el Caribe" disponible en: http://repositorio.cepal.org/bitstream/handle/11362/40528/6/S1601049_es.pdf

CEPLAN (2015) América Latina imaginando el futuro hoy: Los desafíos del pensamiento a largo plazo para el desarrollo. Lima: CEPLAN.

Cordeiro, José Luis, ed. (2012) Latinoamérica 2030: Estudio Delphi y Escenarios. The Millennium Project

David, F. (2003). Conceptos de Administración Estratégica. México DF: Pearson Educación.

Felcman, I. y G. Blutman, (2011). Nuevos modelos de gestión pública. Buenos Aires, Argentina: Editorial Temas. 
Felcman, I. (2017) Nuevos Modelos de Gestión Pública: tecnologías de gestión, cultura y liderazgo después del big bang paradigmático. Buenos Aires. Editorial Errepar.

Felcman, I., G. Blutman y A. Azcorra (2012), Plan Estratégico Agroalimentario y Agroindustrial Participativo y Federal 2010-2020. (PEA $\left.{ }^{2}\right)$. Centro de Investigaciones en Administración Pública.Año 3, Nro.2., Facultad de Ciencias Económicas, UBA.

Felcman, I; G. Blutman, P. Bobeck, I. Gonzalez, y R.Velazquez (2017), “Planeamiento Estratégico Participativo en el Sector Público: Conceptos, metodologías e instrumentos" CIAP - FCE - UBA en http://www.economicas.uba.ar/institutos_y_centros/ciap/

Franklin, E. (2004) Organización de Empresas. México: McGraw Hill.

Hax,A. y N. Majluf (1996) Gestión de empresa: con una visión estratégica. Santiago de Chile:Domen.

Hermida, J., R. Serra y E. Kastika (1992) Administración E Estrategia. Teoría y práctica. Buenos Aires: Ediciones Machi.

Instituto Nacional de la Administración Pública (2008). Glosario de planeamiento estratégico. INAP - Buenos Aires.

Jessop, Bob (2016) The State: Past, Present, Future. Londres: Polity Press.

Krieger, M., A. Azcorra, P.Blanco, G.Blutman, J. Bonifacio, A. Dellasanta y otros.(2013). Estado y administración pública. Perspectivas para el estudio de políticas e instrumentos de gestión pública. Buenos Aires, Argentina: ERREPAR S.A

Lafuente J. (1996). Cuadernos de Direción Estratégica y Planificación. México:Editorial Díaz De Santos.

Lowi,T.J., (1972). System of policy, politics and choice. Public Administration Review. 32, 4:298-310.

Macchiarola de Sigal, V. (2006). Enfoques de planeamiento y racionalidad de la acción. Artículo elaborado en el marco del Curso de Posgrado "Epistemología de las Ciencias Sociales". Universidad de Río Cuarto

Mant, A. (1996). Listos para el trabajo. La movilización del talento para manejar el nuevo mundo. En: "Manejo de lo desconocido. Creando nuevos futuros". Richard Boot; Jean Lawrance, John Morris, Bogotá, Colombia: Mc Graw Hill.

Matus C. (2000). Teoría del juego social. Caracas: Fundación Altadir. 
Matus, C. (1987). Política, planificación y gobierno, Santiago de Chile: Fundación Altadir.

Matus, C. (1993). Guía de análisis teórico, Seminario de Gobierno y Planificación, Método PES. Caracas: Fundación Altadir.

Matus, C. (2007 a). Método Altadir de Planificación Popular (MAPP). Buenos Aires: Lugar Editorial.

Medina Vásquez, J., S. Becerra y P. Castaño (2015) Prospectiva y política pública para el cambio estructural en América Latina y el Caribe. Santiago de Chile: CEPAL.

Ministerio de Agricultura, Ganadería y Pesca de la República Argentina., (2011). Documento de Proyecto. Versión 3. Plan Estratégico Agroalimentario y Agroindustrial, Buenos Aires. Argentina: Ministerio de Agricultura, Ganadería y Pesca de la Nación.

Montero Olivares, Sergio (2014) Una visión prospectiva de la administración pública para la sociedad mundial al 2050. México DF: Instituto de Administración Pública del Estado de México.

OECD (2016) “Estado Futuro 2016: innovación para las personas”- Síntesis de Conferencia Internacional "Estado Futuro 2016: Innovación para las personas" 30 y \& 31 de marzo 2016. Santiago de Chile- OECD \& Laboratorio de Gobierno del Gobierno de Chile - Santiago de Chile

Ortegón, E., F. Pacheco y A. Prieto (2005) Metodología del marco lógico para la planificación, el seguimiento y la evaluación de proyectos y programas. Santiago de Chile, ILPES /CEPAL.

Osborne, D. y T. Gaebler (2002). La reinvención del gobierno. La influencia del espíritu empresarial en el sector público. Barcelona: Ediciones Paidós Ibérica.

Oszlak, O. (2009). "La implementación participativa de políticas públicas: Aportes a la construcción de un marco analítico”. En Belmonte, A. (et. al.): Construyendo confianza. Hacia un nuevo vínculo entre Estado y Sociedad Civil. Buenos Aires: CIPPEC y Subsecretaría para la Reforma Institucional y Fortalecimiento de la Democracia, Jefatura de Gabinete de Ministros, Presidencia de la Nación.

Pichardo Muñiz, A. (2013). “Advances in strategic planning of the public sector in Latin America and the Caribbean: Balance and Perspectives". Index Copernicus Journal, 1, 60-78.

Porter, M., (1993). Estrategia Competitiva, México, D.F.: CECSA,

Prats Catalá, Joamn,(2006), "Veinte años de Modernización Administrativa en los países de la OCDE. Lecciones aprendidas", Seminario Internacional sobre Modernización del Estado, Buenos Aires, Jefatura de Gabinete de Ministros, Buenos Aires, Argentina. 
Programa de Naciones Unidas para el Desarrollo (2009). Manual de planificación, seguimiento y evaluación de los resultados de desarrollo. Nueva York: PNUD.

Ramió Matas, Carles (2015) "La administración Pública del Futuro: la administración '2050”” Programa de Doctorado y Administración Pública - GIGAPP WP 2015/08 Instituto Universitario Ortega y Gasset - Universitat Pompeu Fabra

Sandoval Escudero, C. (2014), "Métodos y aplicaciones de la planificación regional y local en América Latina”, Serie Desarrollo territorial, 17,(2), CEPAL, Santiago de Chile.

Sen, Amartya y Bernardo Kliskerberg (2007) Primero la gente : una mirada desde la ética del desarrollo a los principales problemas del mundo globalizado. Buenos Aires: Grupo Planeta.

Senge, P. (1990). La quinta disciplina. El arte y la práctica de la organización abierta al aprendizaje. Buenos Aires: Ediciones Granica.

Suarez, F. e I. Felcman, (1974). Tecnología y organización. Buenos Aires: El Coloquio.

Superintendencia de Seguros de la Nación República Argentina. (2012 a). Documento conceptual metodológico. Plan Nacional Estratégico del Seguro 2012-2020. Buenos Aires.

Superintendencia de Seguros de la Nación República Argentina. (2012 b). Plan Nacional Estratégico del Seguro 2012-2020. Buenos Aires.

Superintendencia de Seguros de la Nación República Argentina. (2013). A un año de la implementación del Plan Nacional Estratégico del Seguro. Buenos Aires.

Taleb, N. (2009). El cisne negro. El impacto de lo altamente improbable, Buenos Aires: Paidós.

Tzu Sun, (2009). El arte de la guerra. México DF: Gaia Ediciones.

\section{Cómo citar este artículo:}

Felcman, Isidoro y Gustavo Blutman (2018) "La planificación estratégica participativa. Conceptos e instrumentos para nuevos modelos de gestión pública”. Revista Perspectivas de Políticas Públicas vol. 7 No14: 415-447 